\title{
“A TARJA PRETA DA MEDICALIZAÇÃO”: reflexões para a clínica psicológica
}

"Black card of medicalization": reflections for a psychological clinic

"Tarja negra de la medicalización": reflexiones para una clínica psicológica

\author{
Ellen Fernanda Gomes da Silva \\ Universidade Católica de Pernambuco \\ Carmem Barreto \\ Universidade Católica de Pernambuco
}

\begin{abstract}
RESUMO
Este artigo objetiva discutir o fenômeno da medicalização na clínica psicológica, a partir de uma perspectiva fenomenológica hermenêutica. A medicalização da vida ultrapassa a utilização de medicamentos e configura-se como um fenômeno atual que busca explicar e tratar questões da existência humana sob a perspectiva do modelo técnico/biomédico. Na tentativa de refletir essa temática, psicólogas clínicas foram entrevistadas individualmente e narraram acerca de suas experiências frente à medicalização. Na pesquisa realizada constatou-se uma busca, pelos pacientes, em encontrar alívio instantâneo para seus sintomas e seus sofrimentos através do uso de medicamentos. As psicólogas entrevistadas sinalizaram também uma banalização da prescrição medicamentosa, contudo não desconsideraram sua importância em muitos casos. Nessa direção, propomos uma outra perspectiva, a partir da fenomenologia hermenêutica: uma clínica que acolha o sofrimento, as questões da existência, e diz "sim" e "não" ao uso da medicação.
\end{abstract}

Palavras-chave: Ação clínica; Fenomenologia hermenêutica; Medicalização; Psicologia.

\begin{abstract}
This article aims to discuss the phenomenon of medicalization in the psychological clinic, from a hermeneutic phenomenological perspective. The medicalization of life surpasses the use of drugs and is configured as a current phenomenon that seeks to explain and treat questions of human existence from the perspective of the technical / biomedical model. In an attempt to reflect this theme, a cut was made in the doctoral thesis of the principal researcher, in which clinical psychologists interviewed, narrated about their experiences regarding medicalization. The research carried out revealed a search for patients to find instant relief for their symptoms and their suffering through the use of medications. The psychologists interviewed also indicated a banalization of prescription, however they did not disregard its importance in many cases. In this direction, we propose another perspective, from the hermeneutic phenomenology: a clinic that receives suffering, the questions of existence, and says "yes" and "no" to the use of medication.
\end{abstract}


Keywords: Clinical action; Hermeneutical Phenomenology; Medicalization; Psychology.

\section{RESUMEN}

Este artículo tiene como objetivo discutir el fenómeno de la medicalización en la clínica psicológica, a partir de una perspectiva fenomenológica hermenéutica. La medicalización de la vida sobrepasa el uso de drogas y se configura como un fenómeno actual que busca explicar y tratar cuestiones de la existencia humana desde la perspectiva del modelo técnico / biomédico. En el intento de reflejar ese tema, se hizo un recorte en la tesis de doctorado del investigador principal, en el que los psicólogos clínicos entrevistados narraban sobre sus experiencias en relación a la medicalización. La investigación realizada reveló una búsqueda de pacientes para encontrar alivio instantáneo para sus síntomas y su sufrimiento a través del uso de medicamentos. Los psicólogos entrevistados también indicaron una banalización de la prescripción, pero no desconsideraron su importancia en muchos casos. En esa dirección, proponemos otra perspectiva, a partir de la fenomenología hermenéutica: una clínica que recibe sufrimiento, las cuestiones de la existencia, y dice "sí" y "no" al uso de la medicación.

Palabras clave: Acción clínica; Fenomenología Hermenéutica; medicalización; Psicología.

\section{INTRODUÇÃO}

O foco sobre a medicalização foi escolhido como foco deste artigo por apontar um modo de desvelamento do viver nos tempos atuais, no qual predomina uma desconsideração à condição originária da existência humana - a finitude, a angústia, o poder-ser - e a exacerbação do comportamento observável como indicador da maneira "adequada" de existir. Ao falar de medicalização almejamos pensar um movimento para além da prescrição de medicamentos; configura-se, pois, como uma questão social/política que adquire o sentido de invenção e fabricação de "existências medicalizadas".

No que se refere ao uso de medicamentos, a indústria farmacêutica tem anunciado inúmeras fórmulas que prometem apagar nossas dores, driblar os riscos de viver, oferecer alegria, estímulo e consolo. Nessa direção, os medicamentos se apresentam como uma concreta possibilidade de alcançar a saúde, o bem-estar. Essa compreensão de "saúde em pílulas" tem atravessado a clínica psicológica, suscitando um apelo dos pacientes por medicamentos que solucionem ou apaziguem suas questões existenciais. Muitas vezes, a Psicologia, como ciência e profissão, corrobora com os processos de medicalização da vida. O psicólogo, comumente, encaminha o paciente para o profissional responsável por receitar os remédios de "tarja preta" sem antes refletir acerca da necessidade e das repercussões do uso de tais medicações na existência, na saúde do paciente. Uma medicação que poderia ser

Rev. Nufen: Phenom. Interd. | Belém, 11(1), 86-101, jan. - abr., 2019. 
exceção, acaba sendo prescrita rotineiramente, sob os indícios perscrutados pelo médico, pelo vizinho, para o alívio da família e da sociedade.

Mediante tal contexto atual e relevante, no presente artigo, primeiramente objetivamos apontar, a partir de uma revisão de literatura, considerações acerca do fenômeno da medicalização e suas ressonâncias na clínica psicológica e, em seguida, tomamos como possibilidade de diálogo as narrativas de psicólogas, as quais foram convidadas a testemunharem de suas experiências clínicas. Nesse momento, revela-se a possibilidade de acompanha-las em seu fazer clínico, conhecer suas experiências, seus questionamentos, estar próximo ao fenômeno da medicalização em seu próprio movimento de acontecer.

\section{O FENÔMENO DA MEDICALIZAÇÃO}

Conforme Figueiredo (2014), a medicalização, em um sentido amplo, expressa uma resposta contemporânea à procura de uma vida ilusória, ancorada no prazer, na liberdade incondicional e na publicização dos desejos. Tal fenômeno, objetiva a manter o freguês de qualquer farmácia em uma aparente segurança e bem-estar, lugar de refúgio na imersão impessoal do mundo. Interessante notar a exploração midiática a esse respeito: de comerciais bancários a margarinas, propaga-se a concepção de satisfação permanente, de encantamento afastado de qualquer sofrimento, planificação de modos de viver.

Aguiar (2004) realça a discussão sobre a medicalização ao expor que motivações, sensações, emoções estão sendo traduzidas em termos de "baixa serotonina", "alteração da dose do antidepressivo", "oscilação do transtorno bipolar". Dito de outro modo, pessoas apropriam-se de suas experiências como sendo alterações de substâncias químicas cerebrais e buscam solucionar os sofrimentos da vida contemporânea recorrendo, predominantemente, aos psicotrópicos, os quais prometem a homeostase química.

Seguindo essa linha de pensamento, Birman (2014) chama atenção para a patologização daquilo que, antes do advento da regulação dos humores pelos medicamentos, era considerado "normal":

Assim, se a dor e a tristeza sempre marcaram a tensão pré-menstrual, isso foi transformado, na atualidade, numa síndrome específica, que se fez pela psiquiatrização da normalidade. Da mesma forma, a tristeza que sempre existiu na experiência humana foi transformada em matéria-prima das depressões, que se transformaram então numa epidemia, psiquiatricamente induzida, nos anos 1980. Enfim, as variações de humor que sempre marcaram a existência humana foi recentemente psiquiatrizada, para a caracterização da bipolaridade como sendo a nova síndrome, desde o ano 2000, a que se deve medicar com

Rev. Nufen: Phenom. Interd. | Belém, 11(1), 86-101, jan. - abr., 2019. 
psicofármacos diferentes dos que eram utilizados para a depressão. (p. 35, grifos do autor)

Frente a tal contexto, surgem indagações: quais os horizontes de sentido desvelados pelo discurso da medicalização? Quais as ressonâncias dessa visão racional e objetivista do sofrimento humano? De que modo a angústia é acolhida em uma sociedade que busca, com o auxílio da indústria farmacêutica, um estado de satisfação pessoal e coletivo?

Ao atentarmos para o âmbito da clínica psicológica ainda questionamos: diante das promessas de melhora instantânea asseguradas pelos aparatos tecnológicos, como a clínica psicológica pode se posicionar? Como conviver com a crescente prescrição, oferta e solicitação dos medicamentos, os quais se voltam à resolução de crises que atravessam a existência, reduzidas às disfunções orgânicas ou psíquicas? Qual o preço pago para suprimir o sofrimento, através das "pílulas mágicas"? Com tais interrogações não se pretende fazer uma crítica ingênua à medicalização e aos aparatos técnicos; visto que são evidentes os avanços nesse campo e sua relevância em inúmeros casos. A problematização refere-se à absolutização destes recursos, tomados como critério capaz de dar conta dos paradoxos da existência.

Adiante pretendemos discutir, mesmo que brevemente, a progressiva tendência do uso de psicotrópicos em um contexto que vem contribuindo para a medicalização da vida.

Segundo Dantas (2014), anterior ao avanço da farmacologia, os medicamentos eram ervas e preparos caseiros, cujo manejo era passado por gerações na tentativa de resolver os mais variados sofrimentos. A ideia de que poderia haver um remédio específico destinado a cada doença era uma noção estranha à medicina. Contudo, o medicamento vem, ao longo do tempo, se tornando a principal via pela qual a medicina intervém.

Desde o lançamento do antidepressivo Prozac (Fluoxetina), no século $X X$, a Psiquiatria tem se difundido fortemente enquanto especialidade médica, ancorada na legitimidade científica. A "pílula da felicidade" prometia uma ação mais eficaz que os antidepressivos anteriormente produzidos, atrelado a efeitos colaterais e ao potencial de toxicidade significativamente menores. Assim, a medicação se tornou a modalidade hegemônica de intervenção. Atrelado a isso, assistimos a um progressivo abandono de outros saberes - psicossocial, psicológico, espiritual e filosófico (Aguiar, 2004).

Interessante mencionar a pesquisa realizada por Benini e Leal (2016) acerca do uso de psicotrópicos na perspectiva de pessoas com o diagnóstico de esquizofrenia. Segundo as autoras, o uso de medicamentos abarca experiências diversas e de forte influência na maneira pela qual o paciente compreende e se engaja no tratamento. Foi observado que a minoria dos usuários utiliza remédios como uma escolha feita diante de seu diagnóstico; para

Rev. Nufen: Phenom. Interd. | Belém, 11(1), 86-101, jan. - abr., 2019. 
os demais, o uso medicamentoso provém de uma imposição familiar, social e da própria equipe de cuidado. Cabe expor também que alguns pacientes se consideram "cobaias" de uma ciência que ainda não descobriu o remédio para o seu sofrimento. Muitos daqueles que passaram por uma internação psiquiátrica sinalizaram experiências negativas com os remédios, principalmente quando se trata da medicação injetável; mas ressaltaram a relação médico/paciente como forte influenciadora na maneira pela qual vivenciam o uso dos medicamentos.

Frente ao contexto que a pesquisa referida nos aponta, parece que as dimensões da história do paciente recuaram diante do investimento na suposta cura do disfuncionamento corpóreo/mental. Não se trata de negar ou subjugar a importância dos medicamentos em muitas situações. Contudo, será que se o foco do projeto terapêutico se distanciar da doença (e sua medicalização) e privilegiar a experiência do paciente, em sua dimensão singular, as possibilidades de reflexão crítica, autonomia e cuidado de si não poderiam aumentar consideravelmente?

Junto a essas reflexões, é importante trazer os dados da Agência Nacional de Vigilância Sanitária (Anvisa, 2011), os quais sinalizam o crescimento do consumo de psicotrópicos. Os medicamentos, geralmente utilizados para dormir, foram as substâncias controladas mais consumidas pela população brasileira no período de 2007 a 2010. Só em 2010, foram vendidas em torno de 10 milhões de caixas do medicamento Clonazepam - o primeiro da lista. O segundo mais comercializado foi o psicotrópico Bromazepan, com 4,4 milhões de unidades vendidas, seguido pelo medicamento Alprazolam, que registrou 4,3 milhões de unidades.

A Anvisa (2011) também apresenta estimativas de gastos das famílias brasileiras com as substâncias de maior consumo. No caso do Clonazepam, por exemplo, o investimento dos brasileiros, se considerado o preço máximo ao consumidor e a menor faixa de imposto (12\%) aplicável, pode ter chegado a $\mathrm{R} \$ 92,4$ milhões.

Interessante mencionar que no quadro global, o Brasil tornou-se líder na fabricação de Clonazepam em 2013, com 3,2 toneladas produzidas no ano. Segundo os dados do Sistema Nacional de Gerenciamento de Produtos Controlados (SNGPC), somente em março de 2013 foram notificadas a venda de 835.044 caixas de Clonazepam. Tal consumo, apresenta constante aumento tanto nas capitais quanto nas cidades interioranas com um grande salto a partir de 2010, quando as vendas passaram de 755.567 caixas, em 2009, para mais de 1,5 milhão de caixas, um aumento de mais de $200 \%$ (Fórum sobre Medicalização da Educação e da Sociedade, 2015).

No que se refere aos psicoestimulantes, a Ritalina $\AA$, indicada para o tratamento do TDAH (Transtorno do Déficit de Atenção e Hiperatividade), registrou venda de 58.719 caixas em outubro de 2009 e 108.609 caixas em outubro de 2013 , um aumento de mais de

Rev. Nufen: Phenom. Interd. | Belém, 11(1), 86-101, jan. - abr., 2019. 
$180 \%$ em 4 anos. Entre o período de outubro 2007 a setembro 2014, os maiores compradores de Ritalina ${ }^{\circledR}$ encontram-se no interior dos estados de São Paulo, do Rio Grande do Sul e de Minas Gerais. Após o expoente acréscimo no consumo de 2007 até 2012, tal psicoestimulante apresentou queda acentuada de venda em 2013, todavia foi acompanhada pela procura de outras substâncias similares e mais caras, como o Concerta ${ }^{\circledR}$ e o Venvanse ${ }^{\circledR}$ (Fórum sobre Medicalização da Educação e da Sociedade, 2015).

Os dados supracitados apontam a relevância que as substâncias psicoativas vêm ganhando na sociedade atual. $O$ crescimento de uma geração eficiente de psicofármacos parece ter livrado o "comum dos mortais" de um mal-estar desnecessário. Pode ser uma solução satisfatória para um amante desconsolado, uma dona de casa cansada da rotina, um trabalhador que tem de lidar com as pressões do mundo laboral, para crianças indisciplinadas e com dificuldades de aprendizagem, para o jovem estressado e indeciso. Esses são apenas alguns dos inúmeros clientes em potencial para os quais novas fórmulas têm sido desenvolvidas e aperfeiçoadas. Em outros termos, o efeito mais evidente da "saúde em pílulas" tem sido a medicalização de sentimentos anteriormente considerados comuns, pertencentes à própria condição humana.

Interessante notar que, na atualidade, as promessas das medicações mostram-se sedutoras, pois ao invés do tempo, geralmente longo, do processo terapêutico, as substâncias acenam o desaparecimento dos sintomas em semanas. A esse respeito, Figueiredo (2014, p.36) afirma que "a fantasia da medicalização difunde a crença de que a substância química vai livrar o sujeito do sofrimento o mais rápido possível: seria um tratamento rápido, indolor e dispensa trabalho". Nessa direção, o medicamento configura-se enquanto possibilidade de concretização dos ideais contemporâneos de saúde, de beleza e de bem-estar.

Como visto, o vocabulário médico se torna comum, ao passo que intervém na vida cotidiana, criando e alimentando demandas por ajuda farmacológica. Os enunciados das promessas de extinção do sofrimento colocam a medicação em primeiro plano sendo, em muitos casos, a única via de tratamento proposta. Não seria uma restrição do olhar dirigido, unicamente, para a eliminação de sintomas? Restrição da experiência humana em uma formulação neuroquímica? As respostas para tais questões, no momento atual, parecem indicar a primazia do pensamento teorético-explicativo que domina o saber médico e até psicológico. Nisso vigora uma clínica psicológica cujos recursos e modos de intervenção são atravessados, principalmente, pelos labirintos da informação, pelo predomínio da superficialidade, pela funcionalidade do cálculo e do método.

Importa esclarecer que o questionamento acerca da insuficiência do pensamento teorético-explicativo, que atravessa a prática do psicólogo, não parte de uma decisão unilateral das pesquisadoras, mas encontra sua necessidade no modo de ser do fenômeno investigado, o qual, sendo existência humana, não se restringe ao lugar-comum de explicação

Rev. Nufen: Phenom. Interd. | Belém, 11(1), 86-101, jan. - abr., 2019. 
teórica. Autores como Barreto, Silva e Santana (2016) e Feijoo (2017), a partir de aproximações com a Filosofia Hermenêutica, já expressaram a necessidade de acolher o que, habitualmente, é desconsiderado pelo discurso científico. Tais pesquisadores indicam uma prática clínica na qual o homem é compreendido, em sua dimensão singular, enquanto existente aberto à possibilidade da estranheza, do mistério, da angústia de ser.

\section{METODOLOGIA E PROCEDIMENTOS ADOTADOS}

A seguir, apresentaremos a pesquisa realizada. Para tanto, optamos por dialogar com as narrativas de psicólogas que foram entrevistadas com vistas a discutir o objetivo proposto neste artigo: a presença da medicalização na clínica psicológica. É importante expor que adotamos a compreensão de narrativa a partir de Benjamin (1992), a qual caracteriza-se por ser um modo artesanal de comunicação, ressaltando a experiência e aproximando o narrador e a narrativa.

Cabe mencionar que esta pesquisa se configura qualitativa em uma perspectiva fenomenológica hermenêutica. Conforme indica Silva e Santos (2017), as pesquisas nessa perspectiva têm sido bastante propagadas no âmbito acadêmico e da saúde, caracterizandose por interrogar o fenômeno sem a pretensão de adequá-lo às compreensões previamente existentes.

Nessa direção, tal modalidade de pesquisa adota: a dimensão compreensiva da ação humana; a interpretação dos fenômenos humanos e das realidades sociais a partir deles mesmos; o método como "caminho para", o qual se apresenta no próprio caminhar; a verdade como singular; a afetabilidade como condição do pesquisador e do pesquisado, indicando que o conhecimento está fundado na existência e atravessado pelas tradições e preconceitos.

No que se refere aos procedimentos adotados nesta pesquisa, vale mencionar que três psicólogas/colaboradoras - nomeadas de Emma, Luna e Zoe - foram entrevistadas individualmente, com o intuito de narrarem suas experiências (Flick, 2009). Os critérios de inclusão para participação na pesquisa foram: 1) atuar como psicólogo clínico há mais de cinco anos; 2) atender adultos independente da perspectiva teórica adotada. Não foram contemplados profissionais que não correspondem aos aspectos acima referidos.

As entrevistas foram gravadas, transcritas e suas análises foram tecidas a partir da Hermenêutica Filosófica de Gadamer (1986/2012) - processo hermenêutico de produção e interpretação que parte da experiência vivida, envolvendo colaboradores e pesquisadores.

A perspectiva gadameriana possibilita o entendimento do fenômeno em pauta como um movimento contínuo, inconcluso e aproximativo. Tal compreensão também pressupõe uma atitude de receptividade, acompanhando a contação da experiência. Trata-se de um processo hermenêutico de produção e interpretação a partir da experiência vivida, 
envolvendo colaboradores e pesquisadores. Nessa perspectiva, a compreensão não está articulada a uma verdade constituída previamente como conhecimento verificável, adequação do real - veritas. O sentido de verdade aproxima-se de alethéia enquanto desencobrimento, trazer à luz.

Seguindo tal direção, não é possível tomar a questão desta pesquisa como um objeto em si mesmo e sobre ele aplicar uma teoria psicológica ou filosófica. Como a experiência não é um objeto simplesmente dado, mesmo que os protocolos de pesquisas fossem seguidos à risca, ainda assim a experiência escaparia às tentativas de apreensão/controle (Gadamer, 1986/2012).

Por fim, importa salientar que esta pesquisa recebeu a aprovação do Comitê de Ética em Pesquisa com Seres Humanos da Universidade Católica de Pernambuco, sob o número de parecer 1.244.680, conforme Resolução 466/126 do Conselho Nacional de Saúde.

\section{RESULTADO E DISCUSSÃO: NARRATIVA DE PSICÓLOGAS A RESPEITO DA MEDICALIZAÇÃO}

“Contra Rivotril não há vontade de morrer que aguente. O mundo fica quase bom. A vida fica quase bela.

Eu fico quase feliz. Fico tão quase feliz que até paro de chorar". (Falcão, 2005, p. 48-49)

Assistimos a uma expressiva expansão do fenômeno da medicalização nos nossos dias. Concomitantemente às promessas de bem-estar dos psicotrópicos e sua ampla aceitação social, constatamos uma crítica a esse modelo terapêutico como principal via de tratamento para as experiências humanas (Figueiredo, 2014; Rodrigues, 2003). Diante de tal contexto, como o psicólogo clínico pode responder às demandas que the são solicitadas? Como escapar de tal direcionamento terapêutico, já que a prática do psicólogo se encontra atravessada pelo fenômeno da medicalização?

Para compreender melhor o fenômeno da medicalização, dialogamos com a experiência das colaboradoras, as quais trazem inquietações semelhantes às nossas e ajudam a pôr em andamento a questão aqui refletida:

A mãe de uma cliente insistiu por um encaminhamento psiquiátrico e eu fiquei relutante. Minha intervenção foi no sentido de refletir que a medicação não ia responder a demanda da adolescente. [...] É uma cobrança muito grande para que seja a filha perfeita. (Emma)

Rev. Nufen: Phenom. Interd. | Belém, 11(1), 86-101, jan. - abr., 2019. 
Na minha experiência tive que confrontar a expectativa dos clientes em busca de um modelo médico. Qual é o remédio que a senhora vai receitar? Porque doutor fulano passa tal remédio, e você não? (Luna)

Ao aproximar-nos dos depoimentos de Emma e Luna, mediante situações em que foram solicitadas a responder à demanda por medicamentos, percebemos que indagam as expectativas, muitas vezes idealizantes de seus pacientes, de precisarem de doses diárias de remédios para suportar as pressões e sofrimentos cotidianos. Parece que as colaboradoras, ao resistirem ao "canto da sereia" da medicalização, interrogam uma tradição vinculada à Psicologia Clínica a qual tende a corresponder às solicitações de eficiência e eficácia na remissão dos sintomas.

Aqui no consultório o encaminhamento psiquiátrico é pouco. Medicação não é o tratamento, tem outras coisas. Saúde mental é muito complexo [...] A medicação precisa acontecer em casos de transtorno mental severo, por exemplo, quando as pessoas se colocam muito em risco. A medicação ajuda na remissão de sintomas... como um suporte. Mas aí você também vai puxando de outras formas: acolhendo a família, escutando o paciente mesmo que esteja em delírio. Vai ouvindo isso, vai chegando perto...! (Zoe)

$\mathrm{Na}$ narrativa de Zoe, quando relata sua experiência acerca do uso de medicamentos, notamos que não discute sua eficácia, reconhecendo a importância e a funcionalidade em alguns casos; mas reflete também sobre os riscos de assumir a "saúde em pílulas" como intervenção predominante. No encontro clínico, Zoe poderia usufruir dos privilégios de ter a "verdade científica", mas optou por considerar a história do paciente e sua família, escutá-los, acolhê-los. Esse modo de fazer-saber aproxima a prática psicológica do cuidado enquanto solicitude, como atitude de anteposição ao paciente para que possa cuidar do seu próprio poder-ser.

A compreensão de Gadamer (1993/2011) a respeito do diálogo pode auxiliar a aprofundar tal reflexão. Para o filósofo, o diálogo entre clínico e paciente não é algo comum no sistema de saúde do mundo moderno. O que predomina é um monólogo protagonizado, focado no saber do profissional de saúde, não considerando a queixa/demanda do paciente. A narrativa de Zoe aponta em direção ao diálogo enquanto condição de acolhimento, o qual "não é conduzido por ninguém, mas conduz a todos nós" (Gadamer, 1993/2011, p.142). Acolher o outro, nessa ótica, não se configura como ação determinada, meramente, pelos critérios técnico-científicos; mas, por sua vez, não se dará sem a resposta à escuta de um apelo do outro existente, que interrogue/supere as exigências de normalização e medicalização.

Nesse contexto de predomínio do fenômeno da medicalização, Aguiar (2004, p. 149) ressalta a necessidade de: "criar maneiras clínicas de trabalhar com os psicofármacos 
sem enclausurar a escuta, o olhar e a intervenção em um aparato técnico cientificista, que concebe a subjetividade como efeito exclusivo de determinações biológicas, gerando uma clínica que só vê e produz doentes por toda a parte".

Tais reflexões auxiliam a pensar a importância da singularidade da experiência humana em tempos nos quais vigoram teorias explicativas que muito dizem e restringem o adoecer à sintomatologia, negligenciando a dimensão existencial do sofrimento humano. Teorias que oferecem uma medida para a existência e se fundamentam na sustentação de uma sociedade eficiente e eficaz, "alienando" o homem de sua existência. Essa preocupação também se apresenta na experiência de Emma ao relatar sua compreensão acerca de como a existência humana é acolhida no momento contemporâneo:

Existe um modo intolerante da gente lidar com aquilo que faz parte da nossa condição humana: sofrimento, adoecimento, dor. Ficamos presos às medidas e não pensamos, refletimos, nos posicionamos criticamente. [...] O nosso contexto histórico exige muito em uma perspectiva de eficiência e eficácia, estabelecendo um nível de relações em todas as áreas da vida - trabalho, familia, afetividade. É um nível de idealização praticamente inatingível. (Emma)

Somos levadas, pelo depoimento de Emma, a retomar o questionamento a respeito do modelo biomédico, centrado na doença e no projeto de tratamento curativo, seja farmacológico ou psicológico. Refletimos acerca das ressonâncias do modo reducionista de pensar e lidar com o sofrimento que, gradativamente, vai afastando ou até ocultando a ênfase no acolhimento da experiência humana. Esse é o grande risco que corremos! Muitas vezes, na busca de uma solução rápida que atenda às demandas sociais, colocamos em plano secundário a escuta da "dor de existir", em um mundo que, predominantemente, não acolhe a experiência humana, nem a considera como dimensão digna de ser escutada, já que demanda tempo e paciência.

Nessa direção, Emma chama a atenção para a atitude técnica que sobressai na cultura ocidental, a qual privilegia o obscurecimento da experiência humana e objetiva um fim determinado - a eliminação do mal-estar, da doença, da tristeza. "Sua vida, sua história, seus conflitos perdem significância e, em seu lugar, emerge uma lógica de desarranjos químicos que não o implicam; ao contrário, excluem-no como sujeito" (Miguelez, 2014, p.97). Ao desconhecer sua dimensão existencial, esse homem recorre a especialistas e fórmulas farmacológicas a fim de alcançar o caminho da superação da dor. Como não cair em tal armadilha?

Segundo Nascimento (2015), a recorrência usual e simplificadora de ansiolíticos e antidepressivos nos distanciam da experiência apropriativa, afastando o homem da possibilidade de experienciar e apropriar-se do seu sofrimento - aquilo que, em princípio, é o que lhe é mais próprio e singular. Nessa perspectiva, realçamos a importância de uma clínica

Rev. Nufen: Phenom. Interd. | Belém, 11(1), 86-101, jan. - abr., 2019. 
que privilegie a experiência humana e acolha a "dor de existir", acompanhando o paciente no cuidado de si, na busca de encaminhar-se na vida. Para tanto, a linguagem do acontecimento apropriativo configura-se como um solo fértil de retorno ao originário. Tendo em vista a importância da apropriação de si mesmo e da historicidade, o autor supracitado questiona os discursos tradicionalmente consolidados que compreendem o sofrimento como algo a ser minimizado pela força do medicamento.

Considerando as possibilidades compreensivas decorrentes das experiências narradas, cabe atentar para o perigo que a medicalização pode oferecer à existência humana.

Não parece distante o dia em que os modeladores de humor serão de consumo frequente. O homem do futuro poderá acordar pela manhã (se é que dormir ainda será necessário) e decidir qual o temperamento mais útil para aquele dia, tomando para isso, a pílula adequada. Essa possibilidade, em si, não é preocupante. Assustador é pensar que o sujeito poderá estar apagado do projeto humano. Não importa se o humor possa ou não ser quimicamente controlado, desde que o homem não perca sua capacidade de se perguntar: desejo isso? (Silva, 2008, p.149)

Um dos perigos da medicalização consiste na possibilidade de o homem tornarse um "fundo de reserva" a toda espécie de exploração. O destinamento técnico, o qual atravessa a medicalização da vida, pode restringir outros tipos de desencobrimento. Nessa linha compreensiva, a técnica que o homem acredita dominar e com ela controlar o mundo e a própria existência tende a encobrir a capacidade de pensar, de não refletir a respeito do que Ihe é mais próprio. Aqui nos deparamos com a necessidade de manter desperta a reflexão. Tal "disponibilidade" para o pensamento, em última instância, revela-se como uma saída para manter-nos a salvo do perigo de empobrecimento, aniquilamento do humano, em tempos de "pílulas da felicidade".

Ampliando a discussão a respeito da medicalização, dialogamos com a experiência de Emma, quando discute a possibilidade do uso de psicofármacos como modo de conviver com a dependência química, em usuários de um CAPSad ${ }^{1}$. Experiência que tem uma configuração própria, já que aponta para outras questões que não serão aprofundadas na presente reflexão, mesmo que possam ser consideradas. No entanto, tal relato traz um alerta e até uma denúncia de como, muitas vezes, o consumo de medicamentos é direcionado para contornar ou ajudar a família a lidar com o dependente químico.

Os familiares, principalmente as mães acompanhantes, solicitam muito para que os filhos sejam medicados. Comentam se não teria alguma medicação para acalmá-

\footnotetext{
${ }^{1}$ Centro de Atenção Psicossocial Álcool e Drogas
}

Rev. Nufen: Phenom. Interd. | Belém, 11(1), 86-101, jan. - abr., 2019. 
los...e, às vezes, até mesmo com o objetivo de que deixem de fazer uso da substância psicoativa. Interessante que não há uma rigidez por parte dos familiares de que os usuários frequentem o CAPS, mas não deixam de ir pegar a medicação! Já aconteceu de o usuário não ir para o CAPS, mas a mãe chegar no dia da consulta por causa do remédio. (Emma)

Em sua narrativa, Emma sinaliza um outro aspecto da medicalização, qual seja, o caráter de "salvação" dos psicofármacos. As mães/acompanhantes dos usuários parecem endereçar um pedido de ajuda, ao passo que solicitam remédios para acalmar e/ou possibilitar uma mudança de vida dos usuários. Os medicamentos aparentam ter o sentido de concreta possibilidade de resolução para questões pessoais, existenciais e até de dependência química. A utilização de medicamentos se revela como personificação da crença no poder da ciência e no seu discurso curativo, quase se apresentando como única e possível solução. Mas será que o uso de remédios pode ser considerado como uma saída por excelência, ou há outras possibilidades? E, no caso de existir, será que a população em geral "acredita" na importância de intervenções que não passem pela medicalização e pelo prestígio do modelo biomédico?

Continuando seu depoimento, ainda na tentativa de refletir os atravessamentos do consumo dos medicamentos em seu cotidiano de trabalho, Emma realça:

De um modo geral, há uma "cultura de medicalização". Inclusive, assim que o usuário é admitido no CAPSad, já sai com a consulta agendada para o psiquiatra e para a clínica geral. O acompanhamento psiquiátrico é algo visto como fundamental pela gestão, pelos funcionários. Ao mesmo tempo, percebo que as médicas psiquiatras são bem conscientes e, muitas vezes, questionam a necessidade de os usuários terem uma prescrição medicamentosa.

Ao contar de sua experiência, nossa colaboradora salienta a existência de uma "cultura de medicalização", a qual, apressadamente, encaminha o usuário para um atendimento psiquiátrico. Vai se mostrando o quanto a lógica medicalizante aparenta ter um lugar privilegiado no processo de cuidado, compreensão reforçada pelos próprios profissionais do serviço de saúde.

Curioso que Emma destaca um questionamento feito pelas psiquiatras acerca da predominância quanto à prescrição medicamentosa. Abre-se, portanto, a possibilidade de questionar a tradição biomédica desse recurso como única via de cuidado. Estariam as psiquiatras indicando que a consulta médica não necessita ter como fim principal uma receita medicamentosa? Poderia o uso da medicação ser uma das dimensões de acolhimento do usuário de drogas, ao passo que outras possibilidades de cuidado também fossem oferecidas? O encontro entre médico e paciente poderia se configurar como dupla vertente de acolhimento da experiência e resistência às determinações dos Manuais de Psicopatologia?

Rev. Nufen: Phenom. Interd. | Belém, 11(1), 86-101, jan. - abr., 2019. 
Após dialogar com a experiência de Emma, é preciso agora dar outro passo, no intuito de tentar compreender uma questão crucial que esteve implicada nesta reflexão sobre a medicalização.

O diálogo com as reflexões de Birman (2014), ao olhar para a história ocidental, pode indicar um caminho para esse percurso. O autor enuncia uma transformação significativa na utilização de drogas ilícitas e também nas prescritas pela medicina, com finalidade terapêutica. Desde os anos de 1980 e 90, o que passou a ficar em pauta para o usuário dessas drogas foi, por um lado, o aperfeiçoamento das performances frente às demandas existentes na atualidade e o suportar as agruras do mundo presente. É nesse contexto, de desencantamento do mundo e desconsideração da experiência, que as drogas passam a ser aderidas com frequência e até compulsivamente. O uso de substâncias psicotrópicas pode ser considerado uma resposta palpável e rápida para apaziguar e encarar a inospitalidade do mundo? Será que o apelo demasiado ao medicamento pode apontar para a "ausência de pensamentos", apesar de o homem possuir um solo que o destina a pensar, capacidade muitas vezes ofuscada pela tentativa "concreta" de encontrar uma saída rápida e segura, como modo de lidar com tal experiência?

Encontramos uma proximidade dessa reflexão de Birman na fenomenologia hermenêutica, quando Heidegger (1959/2000, p.17) realça que "o enraizamento do homem actual está ameaçado na sua mais íntima essência". Tal desenraizamento provém do espírito de nossa época, marcado pela convocação técnica. Assim, os homens, "enfeitiçados pela rádio e pela televisão" (p.7), veem-se mais próximos desses objetos do que "do próprio campo em torno da casa" (p.7), solo onde o pensamento que reflete "sobre o sentido que reina em tudo o que existe" (p.13) pode florescer.

Nessa direção, há um apelo que convoca os mortais para um habitar outro, em busca de sua terra natal, do seu solo familiar. Assim, somos levadas a refletir e perguntar: como viver em meio à obscuridade do mundo, oferecida pelo pensamento técnico? É preciso continuamente recorrer ao uso e abuso dos psicotrópicos? Não poderia ser oferecida ao homem outra maneira de lidar com os medicamentos, mesmo na era atual?

Seria insensato investir às cegas contra os medicamentos. Necessitamos deles em diversas situações. Contudo, sem muitas vezes nos darmos conta, estamos de tal modo apegados aos remédios que nos tornamos seus prisioneiros. Depositamos nas pílulas o cuidado pelo outro, como também as colocamos na posição de salvadoras de todos os males do homem. Mas há uma outra saída: podemos utilizar os psicofármacos permanecendo, ao mesmo tempo, livres deles, "como algo que não interessa àquilo que temos de mais íntimo e de mais próprio" (Heidegger, 1959/2000, p.23). Nessa postura serena de dizer "sim" e "não" aos medicamentos, situa-se um caminho de proximidade com a experiência, na qual é

Rev. Nufen: Phenom. Interd. | Belém, 11(1), 86-101, jan. - abr., 2019. 
possível abrigar o sofrimento, resguardar o clamor da angústia que nos constitui e nos convoca a testemunhar e experenciar o vigor de nossa existência.

\section{CONSIDERAÇÕES FINAIS}

O caminho trilhado até aqui possibilitou a compreensão da medicalização como um fenômeno presente na prática psicológica. Sem desconsiderar a importância e funcionalidade do uso de medicamentos, as psicólogas/colaboradoras da pesquisa apresentada realçaram um posicionamento crítico mediante as expectativas, muitas vezes idealizantes, de seus pacientes de necessitarem de doses diárias de remédios para silenciar a convocação dada em uma atmosfera de angústia. Nessa reflexão, chamaram atenção para a possibilidade de dizer "sim" e "não" à utilização dos medicamentos, sinalizando que o encaminhamento psiquiátrico pode ser uma das dimensões de acolhimento do paciente à medida que outras possibilidades de cuidado também são oferecidas.

No que se refere à intervenção do psicólogo, foi interrogado o predomínio de uma tradição técnico-científica, a qual está comprometida com tarefas de exatidão, representação, controle. Em tal perspectiva, procura-se respostas para o sofrimento do paciente, bem como adotam-se recursos (como o diagnóstico e medicalização) para a eliminação de sintomas e o encobrimento do sofrimento. O que fica evidente é a necessidade de um questionamento crítico aos ditames de nosso horizonte histórico, a fim de que a clínica ofereça um espaço de reflexão e acolhimento do sofrimento.

Mas, até que ponto a clínica psicológica pode distanciar-se de sua origem metafísica e positivista e partir para assumir outros pressupostos norteadores da ação clínica que não estejam vinculados ao modelo biomédico com realce na medicalização?

Importa realçar que essa ação clínica que toma distância de sua origem metafísica e positivista não se constrói e permanece estática, mas se faz, a cada vez, como caminho. Tal perspectiva é oportuna, principalmente, em tempos que privilegiam a "saúde em pílulas", visto o risco iminente da nomeação prescritiva, do controle, das metas a serem alcançadas, fabricando, assim, a sensação de sermos "senhores da técnica".

Ao dialogar com a compreensão de serenidade e suas ressonâncias (Heidegger, 1959/2000) no âmbito da clínica psicológica, é possível assumir uma posição crítica aos apelos da técnica, sem deixar de considerá-la como destinação. Tal perspectiva, aponta para uma tensão entre: a importância do conhecimento científico para a prática psicológica e também a relevância de uma linguagem que interpreta a palavra sem esgotá-la; a utilização de procedimentos da ciência médica/psiquiátrica como o diagnóstico e a medicalização, mas também o acolhimento da experiência singular, que diz por si mesmo, que se mostra segundo

Rev. Nufen: Phenom. Interd. | Belém, 11(1), 86-101, jan. - abr., 2019. 
a medida de sua possibilidade e não se deixa conformar, restringir às solicitações de normatização e uniformização.

Em uma perspectiva fenomenológica hermenêutica, a clínica que acolhe o sofrimento humano e as questões da existência, surge como uma espécie de resistência em um horizonte histórico atravessado pelo saber/poder que se apropria da vida. Para tanto, demanda-se uma prática psicológica que questione o especialismo da Psicologia, o qual limita intervenções e problematizações, assim como tende a buscar uma representação, um conceito, um diagnóstico. O que se propõe, então, é uma clínica que acompanhe compreensivamente a saga do paciente, sua inquietação e projetos, sustentando um espaço de tematização das demandas trazidas; uma clínica que valorize a expressão daquilo que surpreende, que rompe com o habitual, que angustia.

\section{REFERÊNCIAS}

Anvisa (2011). Boletim de Farmacologia do SNGPC. Disponível em: http://www.anvisa.gov.br/sngpc/boletins/2011/boletim_sngpc_2edatualizada.pdf

Aguiar, A. A. de. (2004). A Psiquiatria do divã: Entre as ciências da vida e a medicalização da existência. Rio de Janeiro: RelumeDumará.

Barreto, C. L. B. T., Silva, E. F. G. da, \& Santana, A. M. (2016). Saúde e prática psicológica: contribuições da hermenêutica filosófica. In Viera Filho, N. G. (Org.). Crises, processos sociais, promoção de saúde (pp. 41-56). Curitiba: CRV.

Benini, I. S. P., \& Leal, E. M. (2016, março). A experiência subjetiva do uso de psicotrópicos na perspectiva de pessoas com o diagnóstico de esquizofrenia. Revista Latinoamericana de Psicopatologia Fundamental, 19(1), 30-42.

Benjamin, W. (1992). O Narrador: considerações sobre a obra de Nikolai Leskov. In Benjamin, W. Sobre Arte, Técnica, Linguagem e Política (pp. 27-57) (M. L. Moita; M. A. Cruz; M. Alberto, trad.). Lisboa: Relógio D’Água.

Birman, J. (2014, agosto). Drogas, performance e psiquiatrização na contemporaneidade. Ágora: Estudos em Teoria Psicanalista, 17(3), 23-37.

Dantas, J. B. (2014). Tecnificação da vida: Uma discussão sobre o fenômeno da medicalização na sociedade contemporânea. Curitiba: CRV.

Feijoo, A. M. L. C. (2017). Existência \& psicoterapia: da psicologia sem objeto ao saber fazer da clínica psicológica existencial. Rio de Janeiro: IFEN.

Figueiredo, L. C. M. (2014). A fantasia de medicalização: Suas origens, sua força e suas implicações. In Menezes, L. S. de., Armando, G. G., \& Vieira, P. (Orgs.). Medicação ou Medicalização? (pp. 25-40). São Paulo: Primavera Editorial.

Flick, U. (2009). Introdução a Pesquisa Qualitativa (3ª ed) (J. E. Costa, trad.). São Paulo: Artmed. 
Gadamer, Hans-Georg. (1993/2011). O caráter oculto da saúde (2ª ed) (L. C. Antônio, trad.). Petrópolis: Vozes.

Gadamer, Hans-Georg. (1986/2012). Verdade e Método I: traços fundamentais de uma hermenêutica filosófica $\left(12^{\mathrm{a}}\right.$ ed) (F. P. Meurer, trad.). Petrópolis: Vozes.

Heidegger, M. (1959/2000). Serenidade ( $2^{\mathrm{a}}$ ed) (M. M. Andrade; O. Santos, trad.). Lisboa: Instituto Piaget.

Miguelez, O. (2014). Medicina, psiquiatria e psicanálise. In Menezes, L. S. de., Armando, G. G., \& Vieira, P. (Orgs.). Medicação ou Medicalização? (pp. 91-102). São Paulo: Primavera Editorial.

Nascimento, C. L. do. (2015). Medicalização e distanciamento da experiência apropriativa. Fenomenologia e Psicologia, São Luís, 3(1), 45-52.

Rodrigues, J. T. (2003, jan./jun.). A medicação como única resposta: uma miragem do contemporâneo. Psicologia em Estudo, Maringá, 8(1), 13-22.

Silva, E. F. G. da; Santos, S. E. de B. (2017, set./dez.) Fenomenologia hermenêutica como caminho para pesquisa qualitativa em Psicologia. Rev. Nufen: Phenom. Interd. Belém, 9(3), 110-126.

Silva, M. M. (2008). A saúde mental e a fabricação da normalidade: uma crítica aos excessos do ideal normalizador a partir das obras de Foucault e Canguilhem. Interação em Psicologia, 12(1), 141-150.

\section{NOTAS SOBRE OS AUTORES:}

Ellen Fernanda Gomes da Silva - Psicóloga. Mestre e Doutora em Psicologia Clínica. Coordenadora da Especialização em Prática Psicológica Clínica na Perspectiva Fenomenológica Existencial (UNICAP). Membro participante do Laboratório de Pesquisa em "Psicologia Clínica Fenomenológica Existencial e Psicossocial" - LACLIFEP (UNICAP). E-mail: ellenfernanda1@hotmail.com

Carmem Barreto - Doutora em Psicologia Escolar e do Desenvolvimento Humano. Pósdoutorado em Filosofia. Professora Adjunta IV da Universidade Católica de Pernambuco, atuando na Graduação em Psicologia e no Programa de Pós-graduação em Psicologia Clínica. Coordenadora do Laboratório de Pesquisa em "Psicologia Clínica Fenomenológica Existencial e Psicossocial - LACLIFEP", vinculado à linha de Pesquisa "Práticas Psicológicas Clínicas e Demandas Contemporâneas" do Programa de Pósgraduação em Psicologia Clínica da Universidade Católica de Pernambuco. E-mail: carmemluciabarreto@hotmail.com

Recebido em: 15/06/2018.

Aprovado em: 05/04/2019. 